Revista Iberoamericana, Vol. LXXI, Núm. 211, Abril-Junio 2005, 505-519

\title{
PECHOS DE LECHE, ORO Y SANGRE: \\ LAS CIRCULACIONES DEL OBJETO Y EL SUJETO EN CECILIA VALDÉS*
}

POR

Christina Civantos

University of Miami

A lo largo de Cecilia Valdés, a medida que hay intentos de imaginar una comunidad cubana separada de la española, hay una serie de metáforas e imágenes del contacto-y del control del contacto- que se repiten. En esta novela romántica y costumbrista del cubano Cirilo Villaverde, aunque la esclavitud se presenta como un mal que se tiene que abolir, la narración refleja una ansiedad acerca del cruce de las fronteras entre lo puro y lo impuro -el yo y el otro. Cecilia Valdés nos cuenta el romance entre Cecilia, una mulata que puede pasar por blanca, y Leonardo, un joven criollo, y el descubrimiento de que son medio hermanos por parte de su padre, el peninsular don Cándido Gamboa. De manera que la novela, cuya versión definitiva sale en $1882,{ }^{1}$ emerge del fervor independentista de los criollos, tanto como del deseo (mayormente frustrado) de crear subjetividades raciales más claramente definidas.

La mayoría de los trabajos críticos sobre Cecilia Valdés se enfocan en la representación de la esclavitud, la raza, y/o la nación en vías de formación, generalmente a través de un análisis de la historia y su voz narrativa. En contraste, en el presente trabajo nos fijamos en un trío de tropos repetidos a través de la obra -lecho, oro y sangre- y analizamos esta serie de imágenes entrelazadas para entender mejor las cuestiones de formación de identidad que subyacen la representación de esclavitud, raza y nación. La historia de Cecilia Valdés se enmarca en un movimiento continuo: además de la circulación de la protagonista, Cecilia, por las calles de La Habana, existe la circulación de la leche de la nodriza negra, la circulación del oro de la criolla rica y del negro liberto, y la circulación -y el derrame- de la sangre. En este trabajo proponemos que estos objetos en movimiento reflejan el temor al otro, un temor que en realidad es el temor de no poder definir el yo -la identidad individual tanto como la nacional. Trazaremos las arterias principales de estas circulaciones con el propósito de ver cómo reflejan el deseo, por parte de Villaverde y los criollos letrados de la época, de construir una comunidad nacional -un circuito contenido- y también los temores que surgen al imaginarse esta comunidad.

\footnotetext{
${ }^{*}$ Le agradezco a Julio Ramos sus comentarios sobre una versión temprana de este trabajo, las discusiones de las que se nutrió y la facilitación de los textos de Julio Jacinto Le Riverend y Anselmo Suárez y Romero aquí citados. También les doy las gracias a Elena Grau-Llevería y Lillian Manzor por sus comentarios minuciosos sobre esta versión del ensayo.

${ }^{1}$ La primera parte de Cecilia Valdés se publica en 1839, la primera edición definitiva en 1882.
} 
Las circulaciones de la leche, el oro y la sangre, además de repetirse a lo largo de la obra, se cruzan y se juntan varias veces a través de la lactancia materna. De modo que hay una red de metonimias que brota alrededor de la figura de la madre de nacimiento y la madre de leche -la nodriza. ${ }^{2}$ María de Regla es la nodriza de "buena y abundante leche” (Villaverde 236) que encontramos en Cecilia Valdés. Ella amamanta a dos de las hijas de Gamboa -Cecilia, la mulata ilegítima, y Adela, una de las hijas legítimas de Gamboa con su esposa criolla, doña Rosa- además de su propia hija, Dolores.

En los discursos novelísticos y de salud de la Cuba de este período, la nodriza es, como señala Julio Ramos, “una figura clave de contacto y comunicación entre las castas” (236, n. 16). María de Regla es un ejemplo perfecto de este fenómeno: su trabajo como nodriza requiere contacto íntimo y crea lazos duraderos. Las que maman su leche son “hermanas de leche” (124). En el caso de Adela y Dolores, “como crecieron juntas, como en realidad mamaron una misma leche, no obstante su opuesta condición y raza, se amaron con amor de hermanas” (125). Este tipo de amamantamiento, aunque se da como consecuencia de la existencia de las jerarquías sociales, crea un vínculo que une a pesar de estas diferencias de clase y raza. La leche no es simplemente consumida; el fluir de este objeto de un cuerpo a otro une a las niñas entre sí y a éstas con la nodriza. El efecto conector de la leche podría interpretarse como una alternativa a las relaciones estratificadas y jerárquicas del sistema racial de Cuba que el narrador critica en ciertos momentos en el texto. Podría ser una manera de unir los varios grupos dentro de la sociedad cubana, de crear una comunidad nacional. Pero, como veremos, la unión, la falta de diferenciación entre el yo (blanco y criollo) y el otro, se ve como un peligro en esta obra.

Al indicar el narrador que, cuando nace Adela, Doña Rosa "no se sentía en condiciones para desempeñar el más dulce de los deberes de madre” (124), nos remite a las discusiones contemporáneas sobre el amamantar. Por ejemplo, en su Memoria sobre la leche el doctor Julio Jacinto Le Riverend opinaba que algunas mujeres no podían dar de mamar por razones físicas, mientras que otras no lo hacían por las influencias y entretenimientos de la sociedad en que vivían. La vida en La Habana, y especialmente la que llevaba su aristocracia, hacía difícil reunir las condiciones necesarias para una lactancia sana (11-12). En el informe de la Real Academia de las Ciencias acerca de la memoria del doctor Cowley, "La lactancia materna, la mercenaria, y la artificial”, se comenta que "si bien es cierto que existen madres en las cuales, por desgracia, hay que emplear la elocuencia más tierna, el lenguaje más persuasivo, para impulsarlas al cumplimiento sagrado de la lactancia [...], hay otras a quienes es preciso retenerlas con mano poderosa" (68).

En Cecilia Valdés, parece ser una cuestión de agotamiento físico, y no de vanidad y placeres que mantienen “en un estado de exaltación el sistema nervioso” (Le Riverend 11), lo que le impide a doña Rosa amamantar a su hija. Como se nos dice en la voz de doña Rosa, se hace “a no poder más” (126). Así y todo, por la mera existencia de la nodriza,

\footnotetext{
${ }^{2}$ Varios críticos han comentado específicamente la figura de la madre en Cecilia Valdés. Véanse, por ejemplo, los dos textos de Williams; Aedo y Feijoo. Aquí nos enfocamos en la madre en tanto y en cuanto, como proveedora, es una de las figuras que participa en la circulación de leche, y como veremos más adelante en la de oro y sangre.
} 
María de Regla, persiste el espectro de la mala madre-la madre que no cumple con su deber sagrado. La nodriza se convierte en suplemento -en el sentido derrideano- de la madre cuando su leche se pone en circulación, lo cual implica una amenaza a la posición de la madre como madre “auténtica”. El cuadro se complica más todavía al tener María de Regla una hija propia recién nacida.

Al darle el encargo de ser nodriza de Adela, los Gamboa le prohíben a María de Regla dar de mamar a su propia hija, Dolores. “[P]ara llenar encargo tan delicioso” (124) es necesario destetar y apartar a Dolores de su madre. Pero la esclava en seguida encuentra cómo criar a las dos niñas -y goza con hacerlo, queriendo a la dos igualmente: "se ponía ambas niñas a los pechos y las amamantaba con imponderable delicia” (énfasis nuestro). María de Regla, la madre por excelencia, goza con cumplir su deber sagrado de madre (y el acto prohibido por su condición de esclava-nodriza) y con su "sagrado cargo" de nodriza (Le Riverend 14). Además su "robustez [...] proveía ampliamente a aquella doble lactancia”.

Doña Rosa al fin descubre esta doble lactancia una noche en que los brazos entrecruzados de las niñas “impedían el mutuo goce del delicioso líquido”. El ama separa de nuevo a la niña negra, pero no castiga a la nodriza ni la cambia por otra porque esto dañaría la salud de Adela. Hasta la leche pura y fresca es variable. Le Riverend hace hincapié en esta característica de la leche de mujer: "Repetimos, sin embargo, que ésta varía sobremanera” (6). Como nos explica el narrador de la novela, reflejando esta idea: "el castigo envenenaría la leche de la esclava”. De manera que el amor maternal de doña Rosa hace que su posición dominante en cuanto a María de Regla sea superada por una de dependencia. La nodriza adquiere ciertos poderes: no puede ser castigada, ni puede ser cambiada por otra. Al convertirse la esclava en ama de leche desplaza algunos de los poderes inmediatos del ama de esclavos.

El hecho de que las niñas - una destinada a ser la esclava de la otra- se "impedían el mutuo goce del delicioso líquido” nos lleva a otra preocupación de la época acerca del amamantamiento: el efecto de la nodriza negra sobre el bebé del burgués blanco. La nodriza no solamente desplaza a la madre y crea un vínculo con el bebé al que le da de mamar, sino que crea vínculos estrechos pero peligrosos entre el bebé blanco y su hermano de leche de color, y por extensión con todas las personas de color. Aunque María de Regla tiene suficiente leche para ambas niñas, los cuerpos mismos de las niñas son un obstáculo que no deja que fluya la leche y se incorpore en cada una de ellas.

Un momento textual que es interesante considerar en conexión con las tensiones alrededor del ama de leche ocurre cuando el narrador describe la reacción compasiva que tienen las señoritas Gamboa e Ilincheta -entre ellas la hija de leche de María de Regladespués de ver que dos esclavos se han suicidado en La Tinaja, el ingenio de los Gamboa. Se nos explican estos sentimientos de la siguiente manera: "Porque ellas, aunque criadas a la leche de la esclavitud, como tiernas flores que abrían sus pétalos a los primeros rayos del sol de la vida, bien podía exclamar con el orador latino: homo sum; humani nihil a me alienum puto" (226, subrayado nuestro). La frase "la leche de la esclavitud" se puede entender de por lo menos en dos maneras. Primero, si "la leche" se lee con sentido metafórico, como lo que nutre a uno desde la infancia a través del contacto íntimo, se entiende que estas señoritas han tenido contacto estrecho con el sistema esclavista desde 
pequeñas. Por esta razón se introduce con un “aunque:” se asume que el que se ha criado en este sistema de opresión y explotación lo acepta y no llora al ver sus resultados terribles. Pero, si se lee "la leche" literalmente y "la esclavitud" metonímicamente como "las esclavas” (tomando la institución por el agente: la esclavitud por las que producen la leche dentro de la esclavitud), llegamos a la razón por la cual las señoritas sí sentirían compasión por los esclavos. El contacto con sus nodrizas no las deja ver a los negros como animales u objetos. Este es el segundo peligro que representa la nodriza, además de desplazar a la madre "uterina", deshace las jerarquías sociales, no sólo la esclavitud, sino las jerarquías raciales en sí.

El horror y temor generalizado frente a lo que representa la leche de la nodriza negra se ve claramente en otros textos de la época, por ejemplo en el ensayo de Anselmo Suárez y Romero, "Vigilancia de las madres". Suárez y Romero culpa a las madres criollas por no cumplir con su deber y exponer a sus hijos, y los de Cuba, a "la palabra de esa nodriza ignorante y corrompida” que "es la que más escuchamos, sus acciones son las que más vemos en esa edad cándida de la infancia” (23). La ansiedad que le causa este tipo de contacto le lleva a decir que:

las madres [blancas] de Cuba [...] dejan a merced de la última clase de la sociedad que alumbre triste la aurora de nuestra inteligencia y afecto, habiendo podido sonreír entre nacarados matices. Ahí se nos inspiran ideas erróneas; ahí brotan las pasiones bastardas, que afirmándose y creciendo después convierten en inútil o vituperable nuestra vida; ahí se corrompe todo, hasta el habla castiza de nuestros mayores.

El peligro de este contacto se sitúa más allá de la contaminación de ideas sobre las razas hasta incluir la contaminación de todo lo “puro”. Sin embargo, el narrador de Cecilia Valdés, al incluir el "aunque” parece no querer indicar esta segunda lectura. A pesar de que el narrador ha calificado la actividad de la nodriza como un encargo "delicioso", una “imponderable delicia” marcada por la "robustez”, recurre a la metáfora de la leche pero en vez de reconocer el rol de la leche literal, tan presente en la historia que cuenta, reprime esa cara del sistema de esclavitud. ¿Cómo puede estar a la vez tan fascinado y a la vez tan horrorizado del papel de la nodriza?

El concepto de lo abyecto tal como lo desarrolla la estudiosa del psicoanálisis Julia Kristeva nos ayuda a entender ésta y otras facetas de la cuestión de las nodrizas. ${ }^{3}$ Tal como lo explica Kristeva, lo abyecto es eso que no es ni sujeto ni objeto sino que es el objeto problemático dentro del sujeto. En general lo abyecto es ese tipo de objeto que el sujeto trata de ingerir o de expulsar, ese tipo de objeto que sale del cuerpo del ser humano pero no parece pertenecerle - 0 , en el caso de la leche, viene de, o llega a formar parte de, otro "yo" con el que no se identifica. Muchos de estos objetos -leche, sangre, saliva, semen, lágrimas y vómito- son líquidos, lo cual intensifica su ambigüedad: el objeto ni se puede contener dentro del cuerpo, ni forma un objeto con límites definibles. Al escurrirse, al

${ }^{3}$ El tema del amamantamiento y los peligros de las nodrizas se discute en Europa por lo menos desde mediados del siglo xviII. Jean-Jacques Rousseau lo trata en el Libro I de Émile ou de l'éducation (255-59), le agradezco a Tony Krupp la referencia. Seguramente el discurso de la ilustración sobre el tema impactó su desarrollo en Cuba. 
desbordarse, al moverse de un cuerpo a otro, borra las fronteras entre el “yo" y el otro, entre cuerpos que se entienden como el fundamento estable y definible del ser. De esta manera, lo abyecto nos hace enfrentarnos con el hecho de que el sujeto depende del objeto para la formación de su identidad. Por lo tanto lo abyecto ejerce sobre el sujeto fascinación y repulsión a la vez.

¿Qué ocurre entonces cuando un objeto como la leche -que podría ser impuro, que es de uno, y no lo es a la vez-circula con valor monetario? El objeto con el valor mercantil más estable, pero que al mismo tiempo tiene una multitud de valores, es la moneda de la época: las onzas de oro y otros metales de menos valor. Según el análisis de Karl Marx, entre las funciones del dinero se encuentran la de servir como medio de circulación, como una medida de valor y como la realización del valor (455-56). En la novela de Villaverde entre las muchas mercancías que circulan por medio del oro -y que cobran valor a través de él-están los esclavos africanos, la comida, los títulos de leyes, los trajes de última moda, y la leche. Entre éstas, la leche (de vaca o cabra y particularmente la de mujer) parece tener una relación más estrecha con lo que posibilita el intercambio de bienes sobre la base de un estándar -el oro.

Cuando el narrador describe la situación de María de Regla nos dice que se le había prohibido dividir entre las dos niñas "sus caricias y el tesoro de su seno" (124, énfasis nuestro). Y efectivamente, sus amos ven su leche como un tesoro, como algo con valor monetario. Unos años antes de llevar a cabo la "doble lactancia”, cuando un hijo recién nacido de la esclava había muerto, Don Cándido le dice que ha pensado que su "buena y abundante leche [...] debe aprovecharse” (236). Don Cándido usa este argumento mercantil y el cuento que a través del doctor Montes de Oca ha alquilado a María de Regla para que amamante a la hija ilegítima de un amigo suyo, para hacer que la esclava nutra con su tesoro a Cecilia. Este arreglo crea “celos” y “fuertes sospechas” por parte de Doña Rosa, las cuales desahoga cuando María de Regla ha cometido otro delito más concreto (la doble lactancia) y la destierra al ingenio después de cumplirse su encargo como nodriza de Adela (125). "El precio del alquiler, dos onzas de oro, las recibió doña Rosa, mes tras mes, con la mayor puntualidad, mientras duró la lactancia, por mano de D. Cándido”. Aunque esto no satisface sus celos, al descubrir años después que el doctor no sabe nada de la nodriza, ni de su alquiler por pagos mensuales, doña Rosa se da cuenta de que su marido la había engañado y llora "sin medida ni consuelo" (148). Le dice a su marido: "El dinero, sí es verdad, no salió del bolsillo de usted, salió del mío; por mejor decir, me lo quitó usted con una mano, para devolvérmelo con la otra” (152). El dinero ha dado una vuelta en un círculo cerrado: no se aprovecha la leche de María de Regla del todo, en vez de un intercambio en el cual se deshace de la leche sustituyéndola con oro, el dinero da vueltas en el mismo espacio sin posibilidad de lucro.

De esta manera, además de los ejemplos de incesto literal y cuasi literal que se encuentran en la obra (los cuales discutiremos más adelante), hay “dinero incestuoso” en la novela. La lactancia de Cecilia por María de Regla forma un circuito cerrado en el que no se distingue entre los lingotes de la familia y los de fuera. En la circulación de la leche que termina siendo una circulación no productiva, un círculo cerrado que no se abre a otros circuitos, vemos la visión de una nación cubana separada de la corona española pero 
demasiado insular. Al imaginar una comunidad cubana, aunque una muy jerarquizada, surge el temor de la circulación repetida, sin diferenciación, en un circuito cerrado.

Después del supuesto intento de alquilar a María de Regla como nodriza, hay otro intento de obtener beneficio de ella que también falla: doña Rosa la trae a La Habana de nuevo bajo la condición de que se alquile y que el dinero vaya a las señoritas Gamboa para comprar alfileres (244). Aunque esclava, es decir mercancía, María de Regla se puede vender a sí misma a través de una "licencia o papel” (261) que lleva la firma de Don Cándido. Pero es doña Rosa quien se ocupa de este asunto, de este papel que la esclava guarda en su pecho. Doña Rosa escribe sobre el pecho de la nodriza y la convierte en mercancía ambulante.

Después de avergonzarse cada vez que saca el papel porque le era repugnante alquilarse o buscar amo, María de Regla se dirige hacia el mercado de la plaza Vieja (26364). Paradójicamente “[t]odo allí era nuevo para ella” y en medio del mercado ella tiene un "aspecto general de forastera” (265). Pero muy pronto se (re-)asimila a lo mercantil y empieza a vender con la carnicera africana Genoveva Santa Cruz. Como María de Regla quiere coartarse (comprar su propia libertad) y se da cuenta de lo remunerativo que es ese trabajo, decide adoptarlo (266-67). Más tarde es como vendedora ambulante de frutas que doña Rosa y Leonardo solicitan sus servicios como intermediaria entre ellos y Cecilia en las Recogidas (292). María de Regla pasa de ser aprovechada por su leche por don Cándido (el peninsular) sin obtener ningún beneficio, a ser comerciante que guarda sus propias ganancias y sirve de ayudante cuando los criollos conspiran en contra del peninsular.

Si seguimos el hilo de la mercancía y los mercados nos encontramos con el que sustituye a María de Regla como proveedora de leche. Al igual que Cecilia es el personaje de la novela que se caracteriza como andariega y callejera (7 y 15), siempre en circulación, la casa en que vive con su abuela es un nudo en el circuito de los vendedores ambulantes. A diferencia de doña Rosa, que evita cualquier contacto con el mercado al mandar a sus emisarios (Dionisio y Reventós) para hacer sus compras, el mercado viene hacia Cecilia y Josefa. La puerta de su casa es el lugar del intercambio. El primero de una serie de vendedores que vienen a la casa es el lechero, “el hombre de la leche,” que le advierte a Josefa que tenga cuidado con sus enemigos y que hace que Cecilia sienta vergüenza por primera vez en su vida (134-36). Este lechero representa otra forma de circulación de la leche y del dinero: el lechero, a diferencia de la nodriza esclava, se separa de la leche (no sale de su pecho), pero sí tiene contacto, control y rendimiento monetario con ella. Mientras María de Regla criaba hijos de leche y todos los contactos y lazos problemáticos que conlleva tal parentesco en un sistema social jerarquizado, el lechero crea compradores, clientes. Lo único que une a este proveedor de leche con sus clientes, y a los clientes entre sí, es el dinero que pasa de mano en mano.

La circulación de la leche en la novela nos revela la fascinación con la figura de la nodriza y sus pechos de leche abundante a la par que el miedo a la conexión entre los distintos circuitos -los vínculos que se crean entre personas de distintas razas, y miedo de la creación de un circuito demasiado cerrado: una nación-isla que se repite sin ningún cambio. No obstante, María de Regla, la figura que más se asocia con la leche, llega a remediar la situación de alguna manera. Al dejar de ser nodriza y no solamente ser 
reemplazada por un comerciante de leche sino reemplazar la leche que manaba de su pecho con el escrito legal y usar esto para convertirse en comerciante ella misma, se difuminan los terrores ligados a la leche. María de Regla termina participando en el proyecto de modernización de la isla al dejar atrás la leche de la esclavitud y fomentar el intercambio capitalista actuando como trabajadora libre.

Además de la leche que se convierte en oro en la persona de María de Regla, también hay una figura que nos presenta muy claramente una "lactancia de oro". Del pecho de la madre desplazada o sustituida, mana otro tesoro. Lo que produce el pecho de doña Rosa no es leche valiosa, sino valor mercantil-oro. Doña Rosa mima a su querido hijo Leonardo con oro y regalos de oro y éstos se asocian a la lactancia materna. El primer caso que nos interesa examinar es el del reloj de oro que le compra a Leonardo. Con mucha alegría doña Rosa pone el reloj en el bolsillo de sus pantalones, que están tendidos en el sofá enfrente de su cama mientras él finge dormir. Pero cuando le parece a doña Rosa que su hijo se ha movido en la cama, de repente duda de su amor materno. El narrador nos indica que ella siente que, aunque su regalo no es malo de por sí, "no resultaría tampoco un bien conocido y sólido de sus demostraciones tiernas y cariñosas con Leonardo, cuando no nacían de méritos contraídos por él, sino de la efusión espontánea e indiscreta de su corazón de madre" (68, énfasis nuestro). Esta "efusión espontánea e indiscreta de su corazón de madre” hacia un hijo que en otra ocasión la madre llama "niño de teta” (290) nos remite a la "efusión espontánea e indiscreta” que es la leche materna.

La "lactancia de oro” también tiene una manifestación mucho más literal, basada no solamente en el lenguaje que el narrador usa para describir emociones, sino también en la descripción de objetos y su contigüidad física, y ésta nos aclara lo que significa el oro en esta obra. Nos referimos al momento en el baile de la Filarmónica en que Leonardo le pide dinero a su madre y ella le da la bolsa que saca de su pecho: "Era de punto de seda, roja, formando dos senos separados por un nudo o lazada en el medio, para dividir el oro entero del menudo y la plata. Se la sacó del seno [...]” (99, énfasis nuestro).

En primer lugar, ¿qué significa el que la leche de su seno se haya reemplazado con oro? Cuando el pensador francés Michel Serres describe el intercambio, el movimiento de la mercancía, señala que el convertir algo en dinero lo inmoviliza. Según él, la única manera de dejar que las cosas varíen y a la vez puedan mantener un valor estable es convertir los bienes en dinero, lo que se ha llamado "el equivalente general” (161). El dinero, lo que Serres llama "el comodín”, aunque cambia y contiene una multitud de posibilidades, se mantiene estable (160-63). De modo que en los casos de María de Regla y doña Rosa la leche se convierte en dinero, un valor que aunque puede circular con más facilidad es, al mismo tiempo, más estable que la leche. Así la leche, variable por esencia, se cambia por lo estable y mantiene su valor abstracto.

En un segundo plano, los senos de seda que doña Rosa saca de su propio seno al igual que separan el dinero de su cuerpo, separan lo puro, lo cien por ciento oro, de lo impuro, los metales menores. La frase "para dividir el oro entero del menudo y la plata” refleja los sistemas monetarios en vigencia en la Cuba del xix y a la vez el afán de mantener la pureza. Bajo los distintos sistemas monetarios en uso en la isla, y aun en momentos en que circulaban a la vez monedas españolas, francesas y cubanas, las monedas de menos valor, 
el menudo, eran de cobre, bronce y plata. ${ }^{4}$ Además, como veremos más adelante, estos metales inferiores a veces se usaban para crear aleaciones que imitaban el oro. En contraste, el oro "entero" -completo, incorrupto e inalterable- es de mayor valor y sirve de símbolo de la pureza en general. Page duBois, en su estudio sobre la conexión entre tortura y verdad, afirma que el oro funciona como símbolo de la pureza. DuBois explica que la palabra que se usaba para tortura -para la extracción de la verdad- en el antiguo griego tenía como primer significado la piedra de toque para probar la pureza del oro (7). Muchos poetas de la antigua Grecia usaron el tropo de la piedra de toque y la metáfora del oro puro (12). DuBois comenta que esta preocupación por diferenciar lo puro de lo ambiguo o mezclado refleja una época de crisis (10). Mary Douglas afirma esta misma idea en su clásico estudio antropológico Purity and Danger:

Creo que las ideas sobre la separación, la purificación, la demarcación y el castigo de las transgresiones tienen como función principal el imponer un sistema sobre una experiencia inherentemente desaseada. Es solamente por medio de la exageración de la diferencia adentro y fuera, alrededor y debajo, macho y hembra, con y contra, que se crea una semblanza de orden. (4)

La experiencia o situación desaseada que existe en la Cuba de mediados del siglo XIX surge de cambios en la composición racial de la isla, cambios en su economía, y cambios en sus relaciones con el gobierno español.

En cuanto al primero de estos cambios, la paranoia que produjo el aumento del número de personas africanas o de color en la isla, así como la idea de la mezcla racial como su futuro resultado, se refleja en el deseo de establecer categorías raciales e identificar con precisión la pureza racial. Cuando estas identificaciones se hacen difíciles se busca la pureza inalterable del oro. Respecto a lo político y económico, uno de los conflictos centrales de la época entre los criollos y la metrópoli es el proteccionismo colonial español. Ramiro Guerra y Sánchez en su historia de Cuba lo describe como: “el viejo conflicto de intereses entre el comerciante y el productor" que se hace "más y más agudo a medida que la riqueza de Cuba alcanzó mayor desarrollo" (297). Entre los criollos hay un deseo de abrir Cuba a otros mercados internacionales, pero, por supuesto, no a una circulación mercantil sin límite. Para hacer de la colonia un país rico se tienen que abrir más circuitos de comercio y a la vez mantener cierto control sobre estos intercambios para retener el mayor porcentaje posible de las ganancias dentro del país. Pero al mismo tiempo, como ya hemos visto, existe el temor de crear una nación demasiado cerrada.

Los “pechos” de dinero divididos de doña Rosa logran hacer lo que los pechos proveedores de leche no pueden -dividen lo puro de lo impuro. De esta manera, responden al deseo de controlar uno de los peligros de la circulación: el peligro de crear un sistema cerrado en el que las razas lleguen a ser inseparables. La bolsa de doña Rosa obstruye el contacto para evitar la confusión entre lo impuro -el metal inferior que a veces se usa para

${ }^{4}$ En 1870, durante la Guerra de los Diez Años, se acuñaron las primeras monedas cubanas que eran solamente de plata y bronce y de valores nominales. La moneda norteamericana también empezó a circular en la isla a finales del xix. Véanse Billetes... 19-22 y 9-10 y 17. 
crear una aleación engañosa- y lo puro, y como consecuencia, impedir la posibilidad de dar a algo el valor que no le corresponde. A diferencia de la leche pura, cuyo valor depende de las “cualidades físicas y morales" de la madre o nodriza (Le Riverend 12), frase que esconde la ideología racial del momento, el oro puro es inalterable. No obstante, hay que controlar y confirmar la pureza del oro. Esta preocupación por distinguir entre el oro puro o auténtico y el mezclado o falso se ve a través de la novela y se puede analizar siguiendo el movimiento del oro trabajado, es decir, el reloj que doña Rosa regala a su hijo. Como el reloj, daremos algunas vueltas hasta llegar a la sangre por medio de circuitos distintos.

Desde el principio de su trayectoria el reloj se relaciona al temor acerca de la falta de autenticidad. Cuando doña Rosa compra el reloj teme no recibir un legítimo reloj ginebrino. Le da a su sirviente Reventós el encargo de comprarlo, enfatizando que debe decirle al relojero que el reloj es para ella, "para prevenirle contra cualquier engaño que pudieran practicar con usted [...] bueno es estar prevenido” (67). Después de regalado, la próxima vez que sabemos del reloj es al llegar la carnicera, Genoveva Santa Cruz, entre los otros comerciantes ambulantes, a la casa de Josefa, la abuela de Cecilia. La vendedora, por medio de un "descuadernado e ininteligible relato" le hace saber a Cecilia que le acaban de robar un reloj a un niño blanco (137). Casi cien páginas más adelante, al leer sobre el estado de Dionisio después de la cuchillada de Pimienta, nos encontramos con el reloj de nuevo. Malanga, el hijastro de la carnicera y el curro prototípico, que levanta al Dionisio herido de la calle, también es el que "levantó” el reloj de Leonardo.

Al final de la minuciosa descripción física de este "tipo sui generis", "la vera efigie de un curro del Manglar,” vemos que Malanga también se involucra en la cuestión de la pureza del oro (245-6). Malanga lleva aretes que el narrador describe de la siguiente manera: "Pendían del lóbulo de sus orejas dos lunas menguantes que parecían de oro, pero que, tocadas en la piedra de toque, estamos seguros, el más inexperto platero las habría declarado de ordinaria tumbaga” (246, énfasis nuestro). Para el joyero, la piedra de toque es eficaz: decide de una vez y sin dudas, hasta sin necesidad de experiencia o habilidad, que los aretes están hechos de una aleación de oro y cobre. Pero esto no impide que Malanga tome estos aretes de metal mezclado como un tipo de piedra de toque: "Luego de llevar ambas manos a las orejas, por si permanecían en su sitio las dos menguantes de tumbaga, diciendo para sí: -No están rompía, no me va a susedel náa” (247). Al considerarlos como prueba de su seguridad decide auxiliar a Dionisio pero pone como base de su decisión lo impuro. No distingue entre lo puro y lo mezclado, confunde sus valores. Sin embargo, de la misma manera que el narrador observa fácilmente que Malanga es curro -un joven negro callejero que vive a base del crimen menor- el joyero reconoce la impureza de sus aretes. Para el narrador y el lector (blancos de la época), el que Malanga use sus aretes como piedra de toque es señal clara de la "impureza" de Malanga mismo. Malanga no puede reconocer el oro puro, no conoce el valor de la pureza, porque no es de 'sangre pura'.

Mientras Dionisio se recupera en la casa de Malanga, el curro le enseña el reloj que le robó a Leonardo amenazándolo con un cuchillo. Pero en manos de Malanga, el reloj para de circular (momentáneamente) y se queda sin valor: Malanga no ha podido cambiarlo por oro en forma de monedas. El reloj se queda enterrado en el piso del cuarto de Malanga porque él, con mala fama y pinta de curro, no puede cambiar la mercancía por 
dinero, y Dionisio, el esclavo de habla y traje tan finos, no se atreve a intentarlo por estar huyendo de la ley. Malanga y Dionisio conocen las normas del control social: lo puro sólo puede estar en manos de personas “puras”, cuando está con personas “impuras” se asume inmediatamente que no le pertenece. La mera idea del platero concienzudo impide la circulación sin límites: no deja que el reloj tenga valor para el curro y el fugitivo. Aquí, como en el caso de los aretes de Malanga, la sangre negra impide la realización del valor del oro. Aunque metal puro, deja de tener éste y cualquier otro valor en manos de los impuros. La sociedad cubana que representa Villaverde aprecia y anhela la circulación del oro, pero solamente en manos de los que se supone que deban tenerlo.

La sangre forma parte de la trayectoria del reloj de oro desde su principio. Después de asegurar la autenticidad del reloj y realizar su compra con monedas de oro, doña Rosa pone el reloj en el bolsillo delantero del pantalón de su hijo, Leonardo. Dentro de los marcos de lactancia e incesto que se encuentran en la obra, este bolsillo nos remite, por contigüidad, a la "efusión espontánea e indiscreta” de la "lactancia” masculina, o sea la eyaculación. Como señala María Teresa Aedo en su discusión de la figura materna en Cecilia Valdés, la relación entre doña Rosa y Leonardo es un “incesto simbólico”:

En efecto, doña Rosa busca en este otro hombre [Leonardo] su confirmación como “madre y esposa leal”, llamándolo “mi vida, mi corazón, mí todo ya en el mundo” (149); besa y abraza constantemente a su hijo y espera ansiosa su regreso por las noches "cual se espera a un amante” (151); se anticipa a sus gustos y se apresura a satisfacerlos "no como madre, sino como enamorada” (151). (8)

Aedo explica que este incesto simbólico “representa la ceguera del grupo criollo, que en su lucha por el poder instrumentaliza su descendencia -su mayor riquezaautotraicionándose para vulnerar el poder del español”. Pero más específicamente, visto a través de la óptica de las circulaciones de leche, oro y sangre, los mimos incestuosos de doña Rosa son una inversión malograda del oro y del afecto. Con su pasión de amante, nutrida por el odio hacia su esposo peninsular, doña Rosa olvida que su hijo es parte de sí misma, parte de su descendencia, de su familia. Impulsa la circulación del oro sin pensar en la de la sangre. De manera que el incesto se puede entender como paralelo a la dinámica de lo abyecto: lo familiar es parte de uno y a la vez no lo es.

Así, por un lado, el reloj puede representar el futuro, hecho de, y encajonado en, el oro -es decir, en la pureza. Representa además el dinero a través del tiempo, o sea el capital. De esta manera invoca los valores de la burguesía de la isla. Al poner este reloj en el pantalón del hijo, doña Rosa invierte en la virilidad del joven criollo, en el futuro de los cubanos de su clase socioeconómica. Pero el reloj sale del bolsillo de Leonardo, pasa por manos de Malanga y después de Dionisio quien tiene el encargo, nunca cumplido, de devolvérselo a su dueño. Antes de volver a ver a Leonardo, Dionisio es detenido y, cuando por fin se ven a través de las rejas de la cárcel, Dionisio le informa a Leonardo que el alcaide lo tiene. Leonardo, ocupado con la búsqueda de Cecilia, no se preocupa por el reloj y nunca volvemos a oír de esta prenda. De modo que el oro invertido en el futuro puro y lucrativo de los burgueses criollos queda encarcelado bajo la autoridad española; es decir, las inversiones de los criollos no los benefician porque no entran en un mercado abierto, 
sino que se quedan en las manos de los peninsulares. Si el reloj en manos de negro pierde su legitimidad y su valor y así revela los temores raciales de la época, el reloj en manos de la administración colonial queda sin valor para la élite criolla y es un reclamo por parte de ésta en contra del proteccionismo económico español. Bajo el proteccionismo colonial el desarrollo capitalista de la isla queda paralizado y el oro no le puede ofrecer enriquecimiento al criollo burgués.

Por otro lado, las monedas de oro que van de madre a hijo tampoco rinden. Doña Rosa, impulsada por la idea de que "respecto a mujeres, Leonardito [al] lado [de don Cándido] es niño de teta" (290), usa su oro para llevar a su hijo al incesto literal. "Pues que irritada la madre contra el padre, por la supuesta persistente violación de la fe conyugal, en venganza o represalia, tramó en secreto con el hijo la mina que debía hacer saltar los parapetos levantados por D. Cándido en defensa del honor de Cecilia Valdés. A su ejecución comprometió doña Rosa su dinero y su influjo” (292). Después de ayudar a su hijo a sacar a Cecilia de la cárcel de las Recogidas y colocarla en una casa alquilada donde nació la hija de ambos, doña Rosa se entera, a través de María de Regla, de la paternidad de Cecilia. "Espantada [...] del abismo a que había empujado a su hijo" lo convence de que tiene que dejar a Cecilia (298). Leonardo, incapaz de amar a quien no sea su madre, cambia de actitud hacia Cecilia "por la grande influencia que sobre él ejercía su enérgica madre. Porque era cosa cierta que si del mozo habían huido todas las virtudes [...], no era menos cierto que aún calentaba su corazón marmóreo por el dulce amor filial” (298).

Pero ya es demasiado tarde. Al igual que las efusiones de leche se convirtieron en las del oro, pasamos de ver a María de Rosa “derrama[r] las onzas sobre la mesa” (66-67) a ver el derrame de sangre. Como hemos observado, a través de la obra se busca la manera de establecer una circulación controlada, ni demasiado cerrada, ni demasiado abierta. Cuando se llega a controlar la circulación de la leche, objeto cambiable y de pureza dudosa que crea lazos que atraviesan las categorías raciales, es por medio de la substitución de ésta por el oro, objeto estable y de pureza comprobable. Y cuando se controla el movimiento del oro es por medio de la categorización racial, pero la sangre suele fluir con tal rapidez y sigilo que las categorías se vuelven inestables, cambiables, impuras, y creadoras de vínculos demasiado estrechos. La sangre, aunque controlada legalmente, tiene un movimiento que escapa al control sociorracial y al final, como la leche y el oro, termina en ese círculo cerrado de las relaciones tan estrechas que son incestuosas.

La circulación de sangre española y africana en Cecilia se presenta en un pasaje que contrasta la descripción de los aretes de Malanga. Aunque cualquiera puede identificar los aretes del curro como metal impuro, respecto a Cecilia el narrador pregunta: “¿A qué raza, pues, pertenecía esta muchacha? Difícil es decirlo. Sin embargo, a un ojo conocedor no podía esconderse [....] Su sangre no era pura” (7, énfasis nuestro). Aquí, aunque el resultado es igual -la impureza, la definición es mucho más difícil; la ambigüedad es tal que se necesita un "ojo conocedor" para decidir el caso. La raza frente a ojos ordinarios no se somete a la identificación eficaz, al control de la categorización y la jerarquización. Como hemos visto, se acude a la pureza estable y clara del oro para disminuir la frustración del deseo de establecer categorías raciales transparentes; no obstante, el oro no esclarece 
la situación de Cecilia, conocida como la "Virgencita de bronce” (20). Y en cierto sentido el oro hasta llega a engañar.

En otra parte de la novela vemos que el oro, usado como metáfora de la riqueza, no es un símbolo claro de la pureza mantenida sino que hay inquietud acerca de cómo se usa. El narrador reflexiona sobre las aspiraciones de Cecilia de casarse con un blanco y concluye diferenciando la situación de Cecilia con la de las mulatas ricas. Éstas pueden entrar en la élite blanca porque, como declara el narrador: "ya se sabe que el oro purifica la sangre más turbia y cubre los mayores defectos así físicos como morales” (52). De modo que el oro puro es manipulado para ofuscar lo impuro. Parece que en la Cuba del xix, ni del oro mismo se puede depender. Y esto se ve aún más claramente cuando consideramos el efecto del oro de doña Rosa. Mientras la nodriza puede corromper con su leche, la madre criolla rica puede corromper con su dinero, que surge de una relación con visos de incesto y ayuda a que se realice una relación literalmente incestuosa.

Tanto la circulación libre de la leche y la sangre negra -la mezcla de razas no percibida, como la pureza del oro que se mantiene a pesar de su circulación (pero pierde su valor según en qué manos esté), terminan en una circulación sin diferenciación en un circuito cerrado. Además del oro que supuestamente paga por la leche de María de Regla y la relación madre-hijo que muestran límites borrosos entre el yo y el otro, el ejemplo central del circuito cerrado es el círculo sanguíneo del incesto de Cecilia y Leonardo. La consanguinidad entre amantes representa una unión que, por no abrirse a otros circuitos, no establece alianzas nuevas; no es productiva en cuanto a coaliciones socio-políticas o a ganancias monetarias y es una mezcla más de sangres. La unión que podría representar la hermandad de leche, o de sangre, solamente crea vínculos peligrosos en los que se pierde la distinción entre el yo y el otro -el otro racial se convierte en el yo familiar.

A partir de las imágenes del oro y de la leche, y los cruces entre éstos, que establecen ciertos circuitos en el discurso de Cecilia Valdés, se ve que a la vez que el temor a la mezcla racial surge del deseo de modernizar la economía cubana, de abolir la esclavitud (permitir la circulación libre de todas las personas de color) y abrir la isla al comercio libre, también se manifiesta el miedo a la creación de un sistema demasiado cerrado, figurado por el incesto, que surge del deseo de desarrollar una nación, una comunidad cerrada. Ambos temores comparten la ansiedad de no poder diferenciar entre el yo y el otro. Para crear una comunidad imaginaria limitada con un sistema económico moderno, y evitar estos horrores de la consanguinidad y los contactos racial literales y metafóricos, hay que imponer orden. Pero a pesar de los intentos de reconocer, categorizar y contener, todavía hay pechos que no dan ni leche ni dinero, sino que dan un flujo incontrolable de sangre -la sangre de la muerte. Además del caso del incesto materno simbólico, leche, oro y sangre se juntan en las figuras de Cecilia, Dionisio y Leonardo. Hay linajes sanguíneos que se juntan para dar lugar al flujo de sangre mezclada dentro de los cuerpos de los descendientes, hay reencuentros de la sangre familiar en amantes incestuosos y en la hija que es producto de esta relación, y hay un flujo de la sangre más allá de los límites de los cuerpos y de la vida.

La segunda vez que el narrador describe el reloj de oro, la segunda vez que el lector lo “ve”, es poco después de la descripción de Dionisio herido en medio de la calle. Se nos dice que la cuchillada de Pimienta “dividió diagonalmente los músculos del lado izquierdo 
del pecho, a la altura de la tetilla, [...] abatiéndole el susto y el fluir de la sangre” (245). El transeúnte que al fin ayuda al herido es Malanga quien le enseña el reloj que robó de Leonardo al amenazarlo con un cuchillo. De modo que volvemos a encontrarnos con el reloj por medio de otro pecho -uno que da sangre como "efusión espontánea”. Pero ni se recupera el reloj ni se controla el flujo de la sangre. Como se preconiza aquí doblemente con el cuchillo que se usa para amenazar a Leonardo y la cuchillada que sufre Dionisio, al final de Cecilia Valdés de la tetilla de Leonardo, el "niño de teta”, mana sangre. El cuchillo del mulato Pimienta "[r]ozándole el brazo a la altura de la tetilla, le entró [...] camino derecho al corazón” y Leonardo cae "salpicándole de sangre el brillante traje de seda blanco” de su novia Isabel Ilincheta (299). Esta sangre que desborda los límites del cuerpo de Leonardo y mancha la pureza de la criolla blanca y virgen es un ejemplo claro de lo abyecto.

Curiosamente, se prefiguran todas estas cuchilladas -la cuchillada con que Malanga amenaza a Leonardo y las dos cuchilladas sangrientas de Pimienta- con un detalle de la descripción de la casa de Josefa, la abuela de Cecilia, en el que la abyección del fluir de la sangre se borra. Muy temprano en la novela, cuando don Cándido Gamboa, todavía conocido por el lector como “el caballero desconocido" (2), visita la casa de Josefa, ambos entran en el cuarto de Charo, la madre de Cecilia, que se ha enfermado a raíz de la separación de su hija. El narrador, al describir el cuarto, incluye el siguiente detalle: "se veía un nicho o retablo de titiritero, donde se veneraba una figura de talla, con traje talar o de mujer, que miraba al cielo y tenía clavada en el pecho una espada, cuya empuñadura parecía de plata" (4). Esta estatua, de una mujer que sufre por una espada de plata (un metal menor aunque no sumamente impuro, dentro del discurso de la novela) que le atraviesa el pecho, también forma parte, aunque quizás de manera más oblicua, de las circulaciones de leche y oro. No obstante, a pesar de la espada clavada en su pecho, no sangra. Es decir, en la figura de madera no se representa la sangre de la herida. Su sangre (africana) no fluye y de esta manera no puede 'contaminar' al pueblo cubano. Esta lectura tiene aún más sentido al tomar en cuenta que, justo después de la descripción de la figura de madera, el narrador nos presenta la bisabuela negra de Cecilia. Describe la anciana negra -“imagen de la muerte, cuya cabeza blanca contrastaba con el ébano de su cuello largo y huesoso" (4) - y nos dice que ella se va del cuarto por la puerta de atrás, espantada por la presencia del hombre blanco. Después de huir del blanco, la bisabuela negra nunca vuelve a aparecer en la obra. La figura tallada representa una fantasía de los burgueses cubanos: una mujer (negra) que sufre en exaltación pero no deja manar su sangre, que desaparece en vez de incorporarse al pueblo cubano -en vez de "salpicarlo de sangre".

Esta figura tallada nos ayuda a ver la abyección principal de la novela: la que se ve al considerar la isla-nación como un cuerpo social, un cuerpo que vacila entre aceptar lo africano y rechazarlo, que queda deseoso y asustado a la vez. De ahí que esté de acuerdo con Juan Gelpí cuando comenta, en su estudio magistral sobre los discursos jerárquicos de Cecilia Valdés, que "La cuchillada de Pimienta [...] no se puede desvincular del seno de María de Regla: esa incisión invalida la posibilidad de leer en el seno de la nodriza un espacio de conciliación nacional” (53). Sin embargo, estoy en desacuerdo con su conclusión final de que la novela "presenta una anti-utopía nacional” (56). A pesar de que la lectura de Gelpí nos permite ver los aspectos reductivos de las lecturas que plantean que 
la obra de Villaverde es una celebración del mestizaje nacional, el presente análisis trata de alejarse de estas interpretaciones resaltando el grado en que Cecilia Valdés muestra una pugna entre el deseo de aceptar lo africano y el de rechazarlo. Al trazar las circulaciones de leche, oro y sangre, vemos que la obra exhibe la tensión entre el anhelo de proclamar una nación unida, o por lo menos factible aunque sea muy jerárquica, y el deseo de mantener muy lejos el disgusto de la mezcla, del vínculo, y hasta de la identificación, entre el yo y el otro. Por ende esta lectura matiza las anteriores lecturas prevalentes de la obra.

Parecería ser que desde la perspectiva del criollo burgués, la nación utópica es precisamente la que acepta lo africano en el cuerpo nacional por medio de la apropiación y el aprovechamiento. La respuesta que ofrece el "ojo conocedor" del narrador frente a la disyuntiva que expresa la obra, es usar al otro para crear otro sistema de circulación: el que promete la modernización. Tanto Dionisio como María de Regla valen oro, revelan la verdad sobre la sangre (son los que informan a otros personajes y al lector acerca de la paternidad de Cecilia) y ponen en funcionamiento, encaminan -literal y figurativamentela modernización. Hemos visto anteriormente cómo María de Regla deja la cuestión de la leche al lechero y se convierte en comerciante ambulante, abriendo el camino a la labor libre de los que antes eran esclavos. En la conclusión de la novela, mientras Cecilia, símbolo por excelencia del contacto, queda encerrada en el hospital mental de Paula, Dionisio, preso por homicidio, es enviado a trabajar en “la composición de calles” (300). Tanto Dionisio como María de Regla son destinados a la creación de un sistema de circulación más regular. Un movimiento más controlado, pero aparentemente más abierto, parece ofrecer la forma de apaciguar el deseo de imponer límites, de definir identidades, en un momento de cambio en Cuba. Pero al final encontramos una versión del olvido de doña Rosa respecto a los lazos filiales (un olvido que impulsa la circulación del oro sin pensar en la de la sangre) y un eco de la fantasía que representa la figura tallada de la casa de Josefa y Cecilia. Al final de la obra, el “ojo conocedor” parece haber olvidado -o tal vez querer olvidar- que ya se ha puesto a circular en el cuerpo de la nación otra niña que elude las categorías raciales (la hija de Cecilia y Leonardo) y con ella otros fluidos incontenibles.

Bibliografía

Aedo, María Teresa. “Cecilia Valdés: Diosas, vírgenes y madres en la identidad mestiza de Cuba”. Acta literaria 20 (1995): 5-22.

Billetes y monedas de Cuba. La Habana: Museo Numismático de Cuba, 1975.

Derrida, Jacques. “Plato’s Pharmacy”. Dissemination. Barbara Johnson, trad. Chicago: University of Chicago Press, 1981.

Douglas, Mary. Purity and Danger. [1966] New York \& London: Routledge, 1991.

DuBois, Page. Torture and Truth. New York \& London: Routledge, 1991.

Feijoo, Gladys. "La madre en la novela Cecilia Valdés de Cirilo Villaverde”. Círculo: Publicación del Círculo de Cultura Panamericano 15 (1986): 79-84.

Gelpí, Juan. "El discurso jerárquico en Cecilia Valdés”. Revista de Crítica Literaria Latinoamericana 17/34 (1991): 47-61. 
Guerra y Sánchez, Ramiro. Manual de historia cubana. La Habana: Cultural, 1938.

Informe acerca de una memoria relativa a "La lactancia materna, la mercenaria, y la artificial” por el Doctor D. Luis M. Cowley. La Habana: [Real Academia de las Ciencias], c.1870.

Kristeva, Julia. Powers of Horror, An Essay on Abjection. Leon S. Roudiez, trad. New York: Columbia University Press, 1982.

Le Riverend, Julio Jacinto. Memoria sobre la leche. La Habana: s.n., c.1850.

Lismore, Thomas. Las monedas de Cuba (1870-1953). La Habana: s.n., 1955.

Marx, Karl. Capital and “Crisis Theory” en The Marx-Engels Reader. Robert Tucker, ed. New York \& London: Norton, 1978.

Ramos, Julio. “Cuerpo, lengua, subjetividad”. Revista de Crítica Literaria Latinoamericana 19/38 (1993): 225-37.

Rousseau, Jean-Jacques. Émile ou de l'Éducation. Oevres complètes, tomo IV. Paris: Éditions Gallimard, 1969.

Serres, Michel. “Meals Among Brothers: Theory of the Joker”. The Parasite. Lawrence Shehr, trad. Baltimore: Johns Hopkins University Press, 1982.

Suárez y Romero, Anselmo. "Vigilancia de las madres”. Colección de artículos. La Habana: La Antilla, 1859.

Villaverde, Cirilo. Cecilia Valdés. [1882]. México: Editorial Porrúa, 1986.

Williams, Lorna V. "From Dusky Venus to Mater Dolorosa: The Female Protagonist in the Cuban Antislavery Novel." Woman as Myth and Metaphor in Latin American Literature. Columbia: University of Missouri Press, 1985. 121-35.

“The Representation of the Female Slave in Villaverde’s Cecilia Valdés”. Hispanic Journal 14/1 (Spring 1993): 73-89. 